\title{
Characteristics and clinical outcome of pT1a-b node-negative breast cancer
}

\author{
(D) Abdilkerim Oyman, ${ }^{1}$ (D) Mustafa Basak, ${ }^{2}$ () Hatice Odabas, ${ }^{2}$ (i) Melike Ozcelik ${ }^{1}$ \\ ${ }^{1}$ Department of Medical Oncology, University of Health Sciences Umraniye Training and Research Hospital, Istanbul, Turkey \\ ${ }^{2}$ Department of Medical Oncology, Dr. Lutfi Kirdar Kartal Training and Research Hospital, Istanbul, Turkey
}

\begin{abstract}
OBJECTIVE: Tumor size, along with other clinicopathological characteristics, has a prognostic role in breast cancer. Recurrence risk tends to rise as tumor size increases. Early T-stage portends a good prognosis. We aimed to investigate the recurrence-free interval rates of T1abN0 group of early breast cancer.

METHODS: Patients diagnosed with pT1a and T1b, lymph node metastasis-negative breast cancer were included in the study. Clinicopathologic characteristics including recurrence, distant metastasis, and final status of the patients were obtained retrospectively from the patient files.

RESULTS: A total of 84 patients included. Twenty-six patients (31\%) had T1a and 58 patients (69\%) had T1b tumors. The 5 -year distant relapse-free survival (DRFS) rate of T1ab tumors was $95.2 \%$. The DRFS rate of T1a tumors was $96.2 \%$, while the rate of T1b tumors was $94.8 \%(\mathrm{p}=0.555)$. The 5 -year RFS rate of T1ab tumors was $90.5 \%$. The RFS rate of T1a tumors was $84.6 \%$, whereas the rate of T1b tumors was $93.1 \%(p=0.359)$. The 5 -year DRFS rate of hormone receptor positive group was $97 \%$, Her-2 positive group was $81.8 \%$, and triple negative group was $100 \%(p=0.041)$. The 5 -year RFS rate of the hormone receptor positive group was $97 \%$, Her- 2 positive group was $72.7 \%$, and triple negative group was $57.1 \%(p=0.001)$. CONCLUSION: The results of the study provided that both T1a and T1b tumors have a good and similar prognosis.
\end{abstract}

Keywords: Distant relapse-free survival; early breast cancer; T1ab.

Cite this article as: Oyman A, Basak M, Odabas H, Ozcelik M. Characteristics and clinical outcome of pT1a-b node-negative breast cancer. North Clin Istanb 2021;8(2):124-129.

T he most common diagnosed type of cancer with the most frequent mortality in women worldwide is breast cancer. Early stage breast cancers include Stage 1 , Stage 2a, and some Stage $2 b$ tumors [1]. Early stage breast cancers have a very good prognosis and 5-year survival rates of about $90 \%$ [2]. As tumor size increases, the risk of lymph node metastasis increases and this situation was found to be associated with recurrence. In addition to tumor size, the biological and histological characteristics of the tumor (such as tumor grade, lymph node metastasis, estrogen and progesterone receptor sta- tus, and the presence of human epidermal growth factor 2 [Her-2] expression) were found to be associated with recurrence [3-6]. In studies conducted in various centers, 5-year relapse-free survival (RFS) rate in patients with T1abN0M0 breast cancer was observed to be over $90 \%$ at 10-year follow-up [7-13].

According to the American Joint Committee on Cancer classification, tumors with a tumor diameter of 1-10 $\mathrm{mm}$ are called $\mathrm{T} 1 \mathrm{ab}$. The subgroup of tumors $<$ or equal to $0.5 \mathrm{~cm}$ is called T1a tumors. On the other hand, tumors which are between $0.6 \mathrm{~cm}$ and $1 \mathrm{~cm}$ are classified as

Received: May 08, 2020 Accepted: October 07, 2021 Online: March 24, 2021

Correspondence: Melike OZCELIK, MD. Saglik Bilimleri Universitesi, Umraniye Egitim ve Arastirma Hastanesi, Tibbi Onkoloji Anabilim Dali, Istanbul, Turkey.

Tel: +90 2166321818 e-mail: drmelike.ozcelik@gmail.com

(c) Copyright 2021 by Istanbul Provincial Directorate of Health - Available online at www.northclinist.com 
T1b tumors. Although tumors in this group have a good prognosis, systemic treatment is recommended for some tumors involving risk factors.

The 2019.3 version of the National Comprehensive Cancer Network (NCCN) guideline, systemic chemotherapy combined with an anti-Her-2 agent trastuzumab treatment is recommended at category 1 level for Her-2 positive tumors above $1 \mathrm{~cm}$, and the same approach is recommended although evidence level is low in T1ab tumors. Adjuvant hormone therapy or systemic therapy is recommended in hormone positive, Her-2 negative group according to the characteristics of the tumor. In the triple negative group, adjuvant systemic treatment is recommended for the tumors above $0.5 \mathrm{~cm}$.

Size of breast cancer tumors at diagnosis has decreased over the past 20-years as a result of early detection by mammography screening. Since detection limits of palpation are accepted to be $1 \mathrm{~cm}$ or bigger, small sub-centimeter invasive breast cancer tumors can be easily detected by mammography $[14,15]$.

In this study, we aimed to investigate distant invasive recurrence-free interval (DRFI) and recurrence-free interval (RFI) rates in the patients with T1abN0M0 breast cancer.

\section{MATERIALS AND METHODS}

\section{Study Design}

The study included 84 female patients diagnosed with T1abN0M0 breast cancer who were treated in the Medical Oncology Clinic of Dr. Lutfi Kirdar Kartal Training and Research Hospital and University of Health Sciences, Umraniye Research and Training Hospital, University of Health Sciences between 1998 and 2018. Clinicopathologic characteristics including recurrence, distant metastasis, and final status of the patients were obtained retrospectively from the patient files. Ethics committee approval of the study was received (date: 11.06 .2020 , number: 237 ).

\section{Statistical Analysis}

Descriptive statistics were used and patient characteristics were tabulated. The quantitative variables were analyzed using proportions and categorical variables were analyzed by Chi-square tests. For DRFI, follow-up ended at distant relapse, death as a result of non-breast cancer, or date of last medical record entry was considered an event. RFI was defined as the time beginning from the breast cancer

\section{Highlight key points}

- Both T1a and T1b tumors have a good and similar prognosis.

- Not only tumor size but also biological and histological characteristics of the tumor should be taken into consideration while individualizing prognosis and treatment desicion.

- Triple-negative and Her-2 positive subtypes have worse prognosis compared with Luminal subtypes even in small breast tumors.

diagnosis to the diagnosis of local or regional recurrence, distant recurrence, death as a result of non-breast cancer, or date of last medical record entry, whichever came first. Time to recurrence and to distant recurrence were estimated according to the Kaplan-Meier method and compared between groups using the log-rank statistic. Twosided $p<0.05$ was considered statistically significant. All analyses were done utilizing the SPSS software package, version 17.0 (SPSS Inc., Chicago, Ill, USA).

\section{RESULTS}

A total of 84 patients were included in the study. Median age was calculated as 50-years. Forty patients (47.6\%) were premenopausal and 44 patients (53.4\%) were postmenopausal. Surgical treatment was applied to all patients. Mastectomy was performed in 32 patients $(38 \%)$ and breast conserving surgery was performed in 52 patients $(62 \%)$. According to TNM classification, 26 patients $(31 \%)$ had $\mathrm{T} 1 \mathrm{a}$ and 58 patients $(69 \%)$ had $\mathrm{T} 1 \mathrm{~b}$ tumors in the pathological examination. The pathological characteristics of the tumors were examined. There were 22 patients (26.2\%) with Grade 1 tumor and 62 patients $(73.8 \%)$ with Grades 2-3 tumor. There were $73(86.9 \%)$ patients who were estrogen receptor and/ or progesterone receptor positive, while there were 11 (13.1\%) patients who were hormone receptor negative. Expression of both receptors was observed in 11 patients (13.1\%). Seven patients $(8.3 \%)$ were observed as triple negative (triple negative).

17 patients $(20.2 \%)$ were administered adjuvant systemic chemotherapy. Anti-Her-2 agent trastuzumab was administered to $10(71.4 \%)$ of 14 patients in Her2 positive group. In all, $66(90.4 \%)$ of the hormonepositive patients received adjuvant hormone therapy. Distant metastasis occurred in total of six patients (7.2\%). Five patients (6\%) had loco regional recurrence. Clinicopathological characteristics of patients are presented in Table 1 . 
TABLE 1. Clinicopathological characteristics of patients $(n=84)$

\begin{tabular}{|c|c|c|c|}
\hline \multirow[t]{2}{*}{ Characteristic, n (\%) } & \multirow[t]{2}{*}{ All patients } & \multicolumn{2}{|c|}{ Tumor size } \\
\hline & & T1a & T1b \\
\hline & & $26(31.0)$ & $58(69.0)$ \\
\hline
\end{tabular}

Age

Median (range), years $50(30-77) \quad 50(42-56) \quad 50(46-59)$

$<65$ years $\quad 77(91.7) \quad 25(29.8) \quad 52(61.9)$

$\geq 65$ years $\quad 7(8.3) \quad 1(1.2) \quad 6(7.1)$

Menopausal status

Post $\quad 44(52.4) \quad 13(15.5) \quad 31(36.9)$

Pre

Surgery

Mastectomy

Lumpectomy

Radiation therapy

Yes

No

Chemotherapy

Yes

No

Tumor grade

Grade 1

Grades 2-3

HT among

R-positive patients

Yes

No

Distant metastasis

MO

M1

Loco regional recurrence

Yes

No

$40(47.6)$

$13(15.5)$

$32(38.0) \quad 12(14.3) \quad 20(23.8)$

$52(62.0) \quad 14(16.7) \quad 38(45.2)$

$52(62.0) \quad 14(16.7) \quad 38(45.2)$

$32(38.0) \quad 12(14.3) \quad 20(23.8)$

$17(20.2) \quad 4(4.8) \quad 13(15.5)$

$67(79.8) \quad 22(26.2) \quad 45(53.5)$

$22(26.2) \quad 3(3.6) \quad 19(22.6)$

$62(73.8) \quad 23(27.4) \quad 39(46.4)$

$67(78.5) \quad 21(25.0) \quad 45(53.5)$

$18(21.5) \quad 5(6.0) \quad 13(15.5)$

$78(92.8) \quad 25(29.8) \quad 53(63.0)$

$6(7.2) \quad 1(1.2) \quad 5(6.0)$

$5(6.0) \quad 3(3.6) \quad 2(2.4)$

$79(94.0) \quad 23(27.4) \quad 56(66.6)$

ER and/or PR status

Positive

Negative

Her-2 status

Positive

Negative

HT: Hormonal therapy; ER: Estrogen receptor; PR: Progesterone receptor; Her-2: Human epidermal growth factor receptor 2; *: Estimated using Pearson's Chi-square test.

The 5-year distant RFS (DRFS) rate of T1ab tumors was $95.2 \%$. The DRFS rate of T1a tumors was $96.2 \%$, while the rate of $\mathrm{T} 1 \mathrm{~b}$ tumors was $94.8 \%(\mathrm{p}=0.555)$. The 5-year RFS rate of T1ab tumors was $90.5 \%$. The RFS rate of T1a tumors was $84.6 \%$, whereas the rate of $\mathrm{T} 1 \mathrm{~b}$ tumors was $93.1 \%(p=0.359)$. According to the breast cancer subtypes, the 5-year DRFS rate of hormone receptor positive group was $97 \%$, Her-2 positive group was $81.8 \%$, and triple negative group was $100 \%(\mathrm{p}=0.041)$. The 5-year RFS rate of the hormone receptor positive group was $97 \%$, Her- 2 positive group was $72.7 \%$, and triple negative group was $57.1 \%(\mathrm{p}=0.001)$. Five-year RFS and DRFS rates of patients according to the tumor size and breast cancer subtype are shown in Table 2. Corresponding survival curves of 5-year RFS and DRFS are presented in Figures 1 and 2, respectively.

\section{DISCUSSION}

The frequency of early diagnosis in breast cancer has been increasing with the help of screening methods such as mammography $[14,15]$. Early-stage breast cancers have a very good prognosis and 5-10 years survival rates of about 90\% [2]. Reported 5-year relapse free survival in patients with T1abN0M0 breast cancer was observed to be over $90 \%$ in 10-year follow-up [7-13]. In our study, DRFS and RFS values were found to be over $90 \%$ in T1ab tumors.

In the study conducted by Theriault et al. [16], only age and tumor subtype in T1ab breast cancer patients had significant impact on RFS and DRFS. Colleoni et al. [17], in their analysis, reported a similar 4-year DFS in T1a and T1b subgroups. In this study, ki-67 level was identified as an independent risk factor. In the study performed by Cancello et al. [18], age and molecular subtype rather than tumor size was found to be significant in local recurrence, distant metastasis, and breast cancer-related deaths. In our study, no difference was observed between the 5-year DRFS and RFS rates in T1a and T1b groups. Multivariate analysis could not be performed due to the insufficient number of patients between the groups.

It is known that prognosis is not only related to increased tumor size but also grade, hormone receptor status, Her-2 status, and lymph node status are effective in breast cancer [19-21]. Her-2 positive breast cancers have more aggressive clinical characteristics. The addition of trastuzumab in the treatment of Her-2 positive breast cancer has a significant effect on both DFS and overall survival (OS). Similarly, triple negative breast cancers are also observed significantly more frequent in local and distant recurrence [22-27]. In our study, DRFS rates were found significantly lower in Her-2 positive group. 
TABLE2. Five-year RFS and DRFS of patients according to the tumor size and breast cancer subtype

\begin{tabular}{|c|c|c|c|c|c|c|c|}
\hline & \multirow[b]{3}{*}{ n (\%) } & \multicolumn{6}{|c|}{ Recurrences during first 5-year of follow-up } \\
\hline & & \multicolumn{3}{|c|}{ Distant } & \multicolumn{3}{|c|}{ Total invasive } \\
\hline & & DRFS (\%) & $95 \% \mathrm{CI}$ & $\mathrm{p}$ & RFS (\%) & $95 \% \mathrm{CI}$ & $\mathrm{p}$ \\
\hline \multicolumn{8}{|l|}{ Tumor size } \\
\hline T1a & $26(31.0)$ & 96.2 & $(89.9-100.0)$ & 0.555 & 84.6 & $(73.0-96.3)$ & 0.359 \\
\hline T1b & $58(69.0)$ & 94.8 & $(90.0-99.6)$ & & 93.1 & $(87.6-98.6)$ & \\
\hline T1ab & $84(100.0)$ & 95.2 & $(91.4-99.1)$ & & 90.5 & $(85.2-95.7)$ & \\
\hline \multicolumn{8}{|c|}{ Breast cancer subtype } \\
\hline HRP & $66(78.6)$ & 97.0 & $(93.5-100.0)$ & 0.041 & 97.0 & $(93.5-100.0)$ & 0.001 \\
\hline Her-2P & $11(13.1)$ & 81.8 & $(62.7-100.0)$ & & 72.7 & $(50.6-94.8)$ & \\
\hline TRN & $7(8.3)$ & 100 & $(100-100)$ & & 57.1 & $(26.4-87.9)$ & \\
\hline
\end{tabular}

RFS: Recurrence-free survival; DRFS: Distant recurrence-free survival; CI: Confidence interval; HRP: Hormone receptor positive; Her-2P: Human epidermal growth factor receptor 2 positive; TRN: Triple negative.

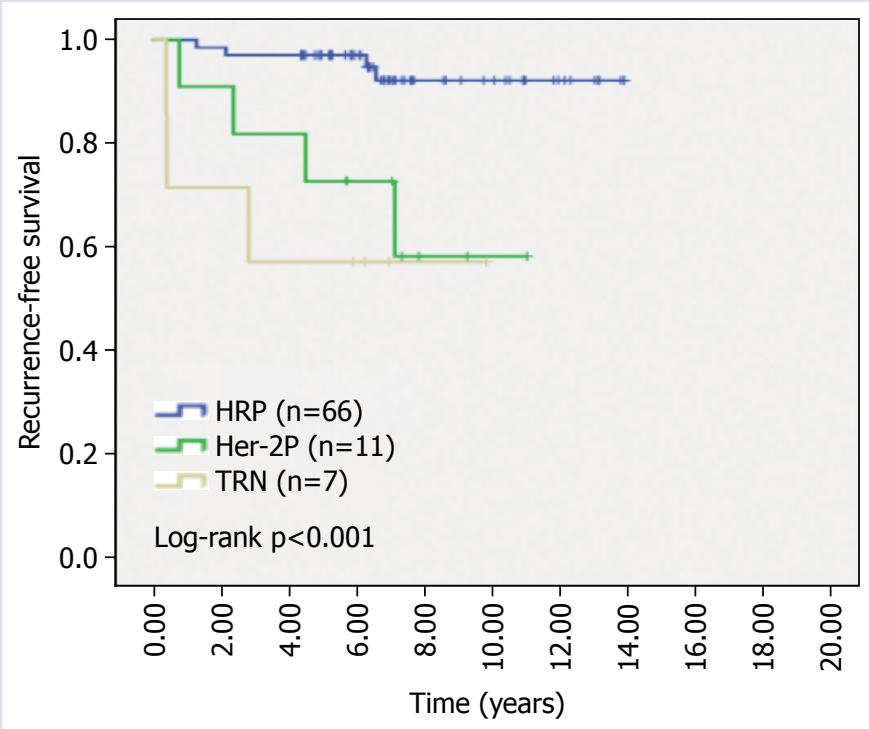

FIGURE 1. Recurrence-free survival by breast cancer subtype.

No distant metastasis was detected in the triple negative group and this may be because of small number of patients. Furthermore, RFS rates were significantly lower in Her-2 positive and triple negative groups.

Houvenaeghel et al. [28] in their large multicenter retrospective cohort study on clinical outcome of $\mathrm{T} 1$ breast cancer, after a median follow-up of 60.5 months, revealed that the OS rate was $97.6 \%$ at 60 months, $95.4 \%$ at 84 months, and $90.7 \%$ at the estimated 10 -year outcome. No significant difference was observed between T1a,

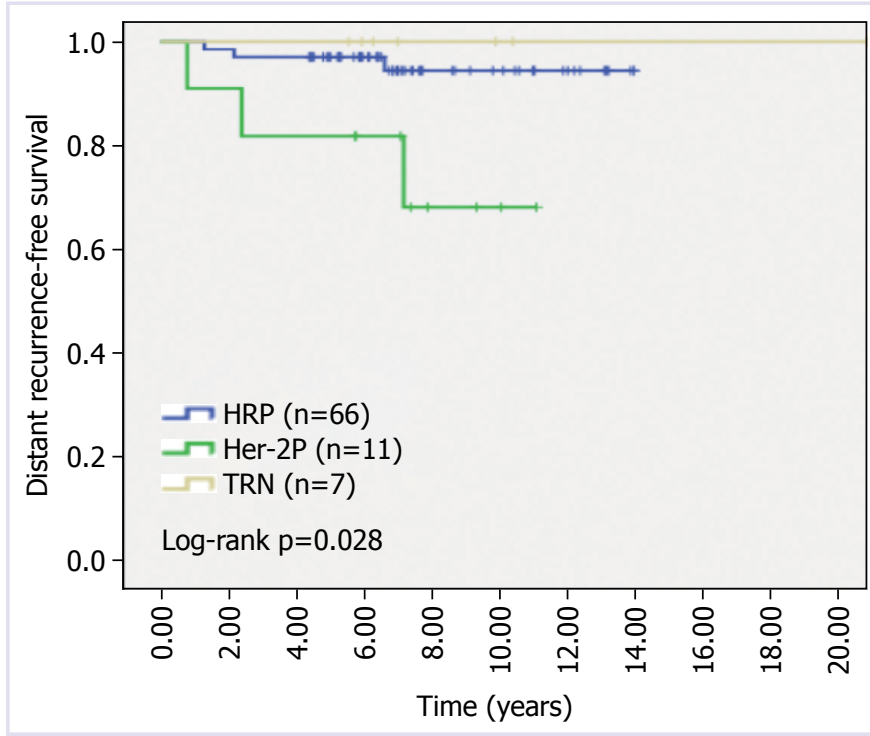

FIGURE 2. Distant recurrence-free survival by breast cancer subtype.

T1b, and T1c tumors $(\mathrm{p}=0.335)$. Multivariate analysis identified AST, LVI, and grade but not tumor size as major determinants of relapse events. A decrease in the 5-year RFS rate from hormone-receptor-positive group to triple-negative group was observed which is consistent with our study. Similarly, in a more recent research regarding prognostic factors of $\mathrm{T} 1 \mathrm{a}-\mathrm{T} 1 \mathrm{~b}$ breast cancer, triple-negative breast cancer had a significantly poorer survival than the other subgroups [29]. In all, despite the institution of adjuvant systemic therapy, triple negative 
T1N0 patients were shown to have greater recurrence and mortality risk.

Breast cancer is a highly heterogeneous disease involving a variety of subtypes each of which displays different biological behaviors. In this study, consisting of $<1 \mathrm{~cm}$, node negative tumors among early stage breast cancer, we found similar survival rates for $\mathrm{T} 1 \mathrm{a}$ and $\mathrm{T} 1 \mathrm{~b}$ tumors. However, RFS rate was different for molecular subtypes with triple-negative having the worst. In clinical practice, utilization of both patient-related prognostic determinants such as age, race, menopausal status, and pathological features including histologic grade, tumor morphology, peritumoral lymphovascular invasion, hormone-receptor, and Her-2 amplification and/or overexpression status should be taken into consideration even if tumor size is $<1 \mathrm{~cm}$ to achieve personalization of adjunctive treatment strategies.

Unable to perform multivariate analysis for DFRS and RFS rates due to insufficient number of patients in terms of distribution of all groups, being a retrospective study, and insufficient sampling constitutes the limitations of our study.

\section{Conclusion}

Individualized treatment plays an important role in breast cancer. It would not be right for the clinician to decide only due to tumor size in the treatment decision. Especially age, molecular subtypes (e.g., Her-2 positive and triple negative) should be taken into consideration.

Ethics Committee Approval: The Health Sciences University, Umraniye Training and Research Hospital Clinical Research Ethics Committee granted approval for this study (date: 11.06.2020, number: 237).

Conflict of Interest: No conflict of interest was declared by the authors.

Financial Disclosure: The authors declared that this study has received no financial support.

Authorship Contributions: Concept - AO; Design - AO, MO; Supervision - AO, MO; Fundings - AO; Materials - HO, MB; Data collection and/or processing - $\mathrm{HO}, \mathrm{AO}$; Analysis and/or interpretation - MB, MO; Literature review - AO; Writing - AO, MO; Critical review $-\mathrm{AO}, \mathrm{MO}$.

\section{REFERENCES}

1. Ferlay J, Soerjomataram I, Dikshit R, Eser S, Mathers C, Rebelo M, et al. Cancer incidence and mortality worldwide: sources, methods and major patterns in GLOBOCAN 2012. Int J Cancer 2015;136:E35986. [CrossRef]
2. Wolters R, Ebner F, Janni W, Novopashenny I, Wöckel A, Kreienberg $\mathrm{R}$, et al; Brenda study group. Do T1a breast cancers profit from adjuvant systemic therapy? A multicenter retrospective cohort study of 325 T1a-patients. Arch Gynecol Obstet 2016;294:377-84. [CrossRef]

3. Fracheboud J, Otto SJ, van Dijck JA, Broeders MJ, Verbeek AL, de Koning HJ; National Evaluation Team for Breast cancer screening (NETB). Decreased rates of advanced breast cancer due to mammography screening in The Netherlands. Br J Cancer 2004;91:8617. [CrossRef]

4. Fisher ER, Costantino JP, Leon ME, Bandos H, Palekar AS, Fisher B, et al. Pathobiology of small invasive breast cancers without metastases (T1a/b, N0, M0): National Surgical Adjuvant Breast and Bowel Project (NSABP) protocol B-21. Cancer 2007;110:1929-36. [CrossRef]

5. Sanpaolo P, Barbieri V, Genovesi D, Fusco V, Ausili Cèfaro G. Biologically effective dose and breast cancer conservative treatment: is duration of radiation therapy really important? Breast Cancer Res Treat 2012;134:81-7. [CrossRef]

6. Livi L, Meattini I, Saieva C, Franzese C, Di Cataldo V, Greto D, et al. Prognostic value of positive human epidermal growth factor receptor 2 status and negative hormone status in patients with $\mathrm{T} 1 \mathrm{a} / \mathrm{T} 1 \mathrm{~b}$, lymph node-negative breast cancer. Cancer 2012;118:3236-43. [CrossRef]

7. Rosen PR, Groshen S, Saigo PE, Kinne DW, Hellman S. A longterm follow-up study of survival in stage I (T1N0M0) and stage II (T1N1M0) breast carcinoma. J Clin Oncol 1989;7:355-66. [CrossRef]

8. Rosen PP, Groshen S, Kinne DW, Norton L. Factors influencing prognosis in node-negative breast carcinoma: analysis of 767 T1N0M0/T2N0M0 patients with long-term follow-up. J Clin Oncol 1993;11:2090-100. [CrossRef]

9. Moon TE, Jones SE, Bonadonna G, Valagussa P, Powles T, Buzdar A, et al. Development and use of a natural history data base of breast cancer studies. Am J Clin Oncol 1987;10:396-403. [CrossRef]

10. Tinnemans JG, Wobbes T, Holland R, Hendriks JH, Van der Sluis RF, De Boer HH. Treatment and survival of female patients with nonpalpable breast carcinoma. Ann Surg 1989;209:249-53. [CrossRef]

11. Stierer M, Rosen HR, Weber R, Marczell A, Kornek GV, Czerwenka E. Long term analysis of factors influencing the outcome in carcinoma of the breast smaller than one centimeter. Surg Gynecol Obstet 1992;175:151-60.

12. Leitner SP, Swern AS, Weinberger D, Duncan LJ, Hutter RV. Predictors of recurrence for patients with small (one centimeter or less) localized breast cancer (T1a,b N0 M0). Cancer 1995;76:2266-74. [CrossRef]

13. Fisher B, Dignam J, Tan-Chiu E, Anderson S, Fisher ER, Wittliff JL, et al. Prognosis and treatment of patients with breast tumors of one centimeter or less and negative axillary lymph nodes. J Natl Cancer Inst 2001;93:112-20. [CrossRef]

14. Vacek PM, Geller BM, Weaver DL, Foster RS Jr. Increased mammography use and its impact on earlier breast cancer detection in Vermont, 1975-1999. Cancer 2002;94:2160-8. [CrossRef]

15. Luke C, Nguyen AM, Priest K, Roder D. Female breast cancers are getting smaller, but socio-demographic differences remain. Aust N Z J Public Health 2004;28:312-6. [CrossRef]

16. Theriault RL, Litton JK, Mittendorf EA, Chen H, Meric-Bernstam F, Chavez-Macgregor M, et al. Age and survival estimates in patients who have node-negative $\mathrm{T} 1 \mathrm{ab}$ breast cancer by breast cancer subtype. Clin Breast Cancer 2011;11:325-31. [CrossRef]

17. Colleoni M, Rotmensz N, Peruzzotti G, Maisonneuve P, Viale G, Renne G, et al. Minimal and small size invasive breast cancer with no axillary lymph node involvement: the need for tailored adjuvant therapies. Ann Oncol 2004;15:1633-9. [CrossRef] 
18. Cancello G, Maisonneuve P, Rotmensz N, Viale G, Mastropasqua MG, Pruneri G, et al. Prognosis in women with small (T1mic,T1a,T1b) node-negative operable breast cancer by immunohistochemically selected subtypes. Breast Cancer Res Treat 2011;127:713-20. [CrossRef]

19. Kwon JH, Kim YJ, Lee KW, Oh DY, Park SY, Kim JH, et al. Triple negativity and young age as prognostic factors in lymph node-negative invasive ductal carcinoma of $1 \mathrm{~cm}$ or less. BMC Cancer 2010;10:557.

20. Park YH, Kim ST, Cho EY, Choi YL, Ok ON, Baek HJ, et al. A risk stratification by hormonal receptors (ER, PgR) and HER-2 status in small ( $<$ or $=1 \mathrm{~cm}$ ) invasive breast cancer: who might be possible candidates for adjuvant treatment? Breast Cancer Res Treat 2010;119:65361. [CrossRef]

21. Joensuu H, Isola J, Lundin M, Salminen T, Holli K, Kataja V, et al. Amplification of erbB2 and erbB2 expression are superior to estrogen receptor status as risk factors for distant recurrence in pT1N0M0 breast cancer: a nationwide population-based study. Clin Cancer Res 2003;9:923-30.

22. Joensuu H, Kellokumpu-Lehtinen PL, Bono P, Alanko T, Kataja $\mathrm{V}$, Asola R, et al. Adjuvant docetaxel or vinorelbine with or without trastuzumab for breast cancer. N Engl J Med 2006; 354:809-20.

23. Piccart-Gebhart MJ, Procter M, Leyland-Jones B, Goldhirsch A, Untch M, Smith I, et al; Herceptin Adjuvant (HERA) Trial Study Team. Trastuzumab after adjuvant chemotherapy in HER2-positive breast cancer. N Engl J Med 2005;353:1659-72. [CrossRef]

24. Slamon D, Eiermann W, Robert N, Pienkowski T, Martin M, Pawlicki
M, et al. Phase III Trial Comparing AC - T with AC - TH and with $\mathrm{TCH}$ in the Adjuvant Treatment of HER2 positive Early Breast Cancer Patients: Second Interim Efficacy Analysis. Presented at the $29^{\text {th }}$ annual San Antonio Breast Cancer Symposium; December 14-17, 2006. BCIRG 006. Available at: https://www.trioncology.org/studies/ bcirg-006/. Accessed Mar 9, 2021.

25. Romond EH, Perez EA, Bryant J, Suman VJ, Geyer CE Jr, Davidson NE, et al. Trastuzumab plus adjuvant chemotherapy for operable HER2-positive breast cancer. N Engl J Med 2005;353:1673-84.

26. Viani GA, Afonso SL, Stefano EJ, De Fendi LI, Soares FV. Adjuvant trastuzumab in the treatment of her-2-positive early breast cancer: a meta-analysis of published randomized trials. BMC Cancer 2007;7:153. [CrossRef]

27. Theriault RL, Litton JK, Mittendorf EA, Chen H, Meric-Bernstam F, Chavez-Macgregor M, Morrow PK, Woodward WA, Sahin A, Hortobagyi GN, Gonzalez-Angulo AM. Age and survival estimates in patients who have node-negative $\mathrm{T} 1 \mathrm{ab}$ breast cancer by breast cancer subtype. Clin Breast Cancer 2011;11:325-31. [CrossRef]

28. Houvenaeghel G, Goncalves A, Classe JM, Garbay JR, Giard S, Charytensky $\mathrm{H}$, et al. Characteristics and clinical outcome of $\mathrm{T} 1$ breast cancer: a multicenter retrospective cohort study. Ann Oncol 2014;25:6238. [CrossRef]

29. Li X, Li J, Wu Q, Zheng H, Feng Y, Xu J, et al. Prognostic factors of T1a-T1b breast cancer: a retrospective cohort study. Int J Clin Exp Med 2017;10:14063-71. 